\title{
Discourse Functions at the Periphery: Noncanonical Word Order in English
}

\author{
Betty Birner \\ Northern Illinois University
}

\begin{abstract}
Speakers have a wide range of noncanonical syntactic options that allow them to mark the information status of the various elements within a proposition. The correlation between a construction and constraints on information status, however, is not arbitrary; there are broad, consistent, and predictive generalizations that can be made about the information-packaging functions served by preposing, postposing, and argument-reversing constructions. Specifically, preposed constituents are constrained to represent discourse-old information, postposed constituents are constrained to represent information that is either discourse-new or hearer-new, and argument-reversing constructions require that the information represented by the preposed constituent be at least as familiar as that represented by the postposed constituent (Birner \& Ward 1998). The status of inferable information (Clark 1977; Prince 1981), however, is problematic; a study of corpus data shows that such information can be preposed in an inversion or a preposing (hence must be discourse-old), yet can also be postposed in constructions requiring hearer-new information (hence must be hearer-new). This information status - discourseold yet hearer-new - is assumed by Prince (1992) to be non-occurring on the grounds that what has been evoked in the discourse should be known to the hearer. I resolve this difficulty by arguing for a reinterpretation of the term 'discourse-old' as applying not only to information that has been explicitly evoked in the prior discourse, but rather to any information that provides a salient inferential link to the prior discourse. Extending Prince's notion in this manner allows us to account for the distribution of noncanonically positioned peripheral constituents in a principled and unified way.
\end{abstract}

\footnotetext{
* I would like to thank Barbara Abbott, Ariel Cohen, Daniel Hole, Werner Frey, Günther Grewendorf, Liliane Haegeman, Mutsuko Endo Hudson, Hans Kamp, Jeff Kaplan, Andy Kehler, Manfred Krifka, Nevin Leder, Anikó Lipták, Claudia Maienborn, Alan Munn, Fritz Newmeyer, Cecilia Poletto, Dennis Preston, Sophie Repp, Cristina Schmitt, Ben Shaer, Nicholas Sobin, Yishai Tobin, Gregory Ward, and Malte Zimmermann for helpful comments and suggestions. I am also grateful to Gregory Ward and Beth Levin for providing naturally occurring data, and to Brittany Bergstrand and Theresa Kirner for help with database construction and coding. Earlier versions of this paper were presented at Northern Illinois University, San Diego State University, Michigan State University, and the Eighth International Columbia School Conference on the Interaction of Form and Meaning with Human Behavior, as well as at the Workshop on Dislocated Elements in Discourse at the Zentrum für Allgemeine Sprachwissenschaft in Berlin. I am grateful to the audiences at those talks for their very helpful comments and suggestions. Needless to say, all remaining errors are my own.
} 


\section{Introduction}

The English language provides its speakers with a variety of noncanonical syntactic means for expressing a given proposition. Although these noncanonical-word-order utterances may be truth-conditionally equivalent to the corresponding canonical variants, they differ in their relationship to the discourse context. This paper focuses on noncanonical constructions that exploit peripheral sentence position to preserve discourse coherence, and shows how this coherence is attained via inferential links between the current utterance and the prior discourse.

Coherence in discourse has two aspects, one having to do with intersentential relevance and the other with intrasentential ordering. Violating either aspect will result in an incoherent discourse. The first aspect, having to do with intersentential relevance, involves our assumption that the utterances in a discourse bear some relationship to each other. This is the notion of coherence discussed, for example, in Kehler 2002. Kehler considers the way in which hearers infer specific coherence relations among the sentences in a discourse in order to preserve their assumption that the discourse is in fact coherent, and notes that 'the need to establish coherence is basic to our natural language understanding capacity' (2002: 3 ). That is, we as communicators will go to a fair amount of trouble to infer connections in order to preserve our belief that a discourse is coherent, as Grice (1975) was the first to observe.

My concern in this paper is with the second aspect of coherence, having to do with intrasentential ordering - that is, with the ordering of information within an utterance. While at one level a coherent discourse requires that individual utterances have something to do with one another, at another level a coherent discourse requires that the information within each utterance be presented in an order that will help the hearer to link the information expressed in the current utterance with information expressed in the prior discourse. In this sense a coherent discourse is one in which the information expressed in each sentence is presented in a coherent order - an order that facilitates processing. This ordering of information is what Chafe (1976) calls information packaging. Information packaging is done syntactically; that is, we choose one syntactic construction over another, in part, in order to package information in a way that will facilitate the hearer's processing of the discourse. A coherent discourse, in short, is easier to process than an incoherent one.

In this paper I review the ways in which speakers use peripheral sentence positions to preserve coherence and facilitate processing, and I review current models of the informational relationships that can hold between elements in a discourse. Finally, I address the problematic issue of 'inferable' information and suggest a model that promises to offer a unified account of the use of noncanonical syntactic constructions to preserve discourse coherence. This 
paper, then, addresses two basic questions: First, how do speakers and hearers use peripheral elements to create coherent discourses? And second, what part do inferences play in the construction of a coherent discourse?

\section{Background}

One of the primary factors contributing to the coherence of a discourse is the existence of informational relationships, or LINKS, among the utterances that make up the discourse (Birner \& Ward 1998). These links facilitate discourse processing by helping the hearer to track relationships among discourse entities. Speakers use a wide variety of linguistic forms, in turn, to mark these relationships, and thereby to facilitate the hearer's processing of the discourse. One obvious example is definiteness: If I choose to utter the definite NP the cat rather than the indefinite $a$ cat, my hearer will assume that I am referring to a cat that I believe they can already identify, and will search their discourse model for such a cat rather than assuming that they need to add a new one. That is, the use of the definite article cues the listener to look for an appropriate referent among their store of already evoked information rather than adding a new entity to the discourse model. ${ }^{1}$

Noncanonical syntactic constructions are another way of marking these relationships. Canonical constructions typically do not have constraints on their use; rather, they are unmarked and constitute the default case. Noncanonical constructions, in contrast, are marked and frequently serve an information-structuring purpose. Consider (1a), in which the noncanonical construction known as inversion marks the link between one mention of a tank and a subsequent mention:

(1) a. They have a great big tank in the kitchen, and in the tank are sitting all of these pots.

(Jeff Smith, Frugal Gourmet, 6/17/89)

b. They have all of these pots in the kitchen, and \#in a great big tank are sitting all of the pots.

In the italicized inversion in (1a), the preposed tank is linked to the earlier mention of a great big tank. When the link is instead between the postposed pots and the prior discourse, as in (1b), the discourse is incoherent and therefore infelicitous.

\footnotetext{
${ }^{1}$ This is of course a simplification of the rather complex issue of definiteness; see Abbott 2003 for a review. See also Birner \& Ward 1994 for an argument that identifiability is a sufficient but not necessary condition for use of the definite article.
} 
Example (2a) presents the canonical variant of the inversion in (1a), while (2b-r) illustrate some of the many semantically equivalent ways English offers for saying (semantically) the same thing:

(2) a. All of these pots are sitting in the tank.

b. In the tank are sitting all of these pots.

c. There are all of these pots sitting in the tank.

d. In the tank there are sitting all of these pots.

e. There are sitting in the tank all of these pots.

f. In the tank all of these pots are sitting.

g. All of these pots, they're sitting in the tank.

h. These pots, they're all sitting in the tank.

i. In the tank, that's where all of these pots are sitting.

j. It's in the tank that all of these pots are sitting.

k. It's in the tank that are sitting all of these pots.

1. It's all of these pots that are sitting in the tank.

$\mathrm{m}$. Where all of these pots are sitting is in the tank.

$\mathrm{n}$. In the tank is where all of these pots are sitting.

o. What is sitting in the tank are all of these pots.

p. All of these pots are what is sitting in the tank.

q. It's where all of these pots are sitting, in the tank.

r. They are what is sitting in the tank, all of these pots.

Why would the English language devote such extensive syntactic resources for providing speakers with options for saying what amounts to the same thing? The answer, as argued in Birner \& Ward 1998, is that these options allow speakers to mark the information status of the various elements that make up the proposition - roughly speaking, what's new, what's known, and what's linked to the prior discourse. Because noncanonical constructions are used in consistent and characteristic ways to structure information, the use of a particular construction makes it possible for the hearer to infer the status of the constituents of the utterance, which in turn makes it easier to identify the relationships among the utterances and the information evoked in the utterances, and easier to process the discourse.

I have said that noncanonical constructions are used in consistent and characteristic ways to structure information, and one might ask whether that means that individual constructions are consistent in how they structure 
information, or whether there are consistent patterns across constructions with respect to how information is structured. The answer is both: not only do individual construction mark information status in consistent ways, but one can also identify uniform patterns of information packaging among syntactically related classes of constructions in English.

It has long been known that many languages tend to structure discourse on the basis of an 'old/new' principle; that is, in any given sentence, linguistic material that expresses information that is assumed to be 'given' (in some sense) tends to be placed before that which is assumed to be 'new' (in some sense). English is such a language; this principle can be seen to be at work in (1a), in that the previously mentioned tank is placed before the new and unpredictable all of these pots. If the prior context is altered so that the pots are given and the tank is new, as in (1b), the discourse becomes infelicitous. Since the early Prague School work on syntax and discourse function (e.g., Firbas 1966), researchers have amassed evidence for this correlation between sentence position and givenness in the discourse, as expressed in the 'givennew contract' of Halliday 1967 and Halliday \& Hasan 1976, which states that given information tends to appear closer to the beginning of a sentence, while new information tends to appear closer to the end.

How to define the relevant notion of givenness, however, has been a controversial issue. Chafe (1976) defines given, or old, information, as 'that knowledge which the speaker assumes to be in the consciousness of the addressee at the time of the utterance', while new information is defined as 'what the speaker assumes he is introducing into the addressee's consciousness by what he says'. But 'consciousness' is an ill-defined notion. Other notions of 'old' information have relied on notions like predictability and shared knowledge (Prince 1981). Prince rejects these notions in favor of assumed familiarity, reflecting the fact that only an omniscient observer can know what knowledge is in fact shared between interlocutors, while actual language users have to operate on the basis of what they assume to be familiar to their interlocutors.

Prince 1992 distinguishes three basic notions of given versus new information, which in turn constitute the three primary factors that determine the structuring of information in English. The first two distinctions are between, on the one hand, discourse-old and discourse-new information and, on the other hand, hearer-old and hearer-new information. Discourse-old information is that which has been explicitly evoked in the prior discourse (or its situational context), whereas discourse-new information is that which has not been previously evoked. Hearer-old information is that which, regardless of whether it has been evoked in the current discourse, is assumed to be known to the hearer, while hearer-new information is assumed to be new to the hearer. These two distinctions can be seen as a matrix of cross-cutting dichotomies: 
Table 1: Prince 1992

Hearer-old: Hearer-new:

\begin{tabular}{l|l|l|}
\cline { 2 - 3 } Discourse-old: & $\begin{array}{l}\text { Evoked (previously } \\
\text { evoked in the discourse) }\end{array}$ & (non-occurring) \\
\cline { 2 - 3 } Discourse-new: & $\begin{array}{l}\text { Unused (assumed to be } \\
\text { known; not yet evoked) }\end{array}$ & $\begin{array}{l}\text { Brand-new (assumed new } \\
\text { to discourse and hearer) }\end{array}$ \\
\cline { 2 - 3 } &
\end{tabular}

The terms 'evoked', 'unused', and 'brand-new' are from Prince 1981 and show how the cells of the matrix formed by the categories of Prince 1992 correspond to the categories defined in that earlier work. Thus, previously evoked information is both hearer-old and discourse-old, brand-new information is both hearer-new and discourse-new, and unused information is hearer-old but discourse-new - i.e., it is assumed to be known to the hearer but has not yet been evoked in the current discourse. Thus, consider (3):

(3) Gov. Rod Blagojevich, while scaling back a massive capital program, said Friday he would endorse a $\$ 3.6$ billion state construction budget that includes new money to build schools and millions of dollars for legislative pork-barrel projects.

(Chicago Tribune, 8/23/03)

Here, the NP Gov. Rod Blagojevich represents information that is discoursenew but hearer-old (in that readers of the Chicago Tribune are assumed to know the identity of the governor of Illinois), the NP a \$3.6 billion state construction budget represents information that is both discourse-new and (assumed to be) hearer-new, and the pronoun he represents information that is both discourse-old and hearer-old (since its referent has been mentioned earlier in the same sentence). Information that is discourse-old but hearer-new is predicted not to occur, on the grounds that a speaker typically believes that the hearer is paying attention and thus that what has been evoked in the discourse is also known to the hearer (Prince 1992). Notice that Prince uses these terms primarily to talk about the discourse or hearer status of an entity, i.e., whether the entity has been mentioned in the discourse model or is assumed to exist in the hearer's knowledge store. I will be using them more broadly to describe the status of not only entities but also attributes, states, and relations - i.e., any information that can be familiar or unfamiliar.

In addition, many constructions require that a particular open proposition (in the sense of Prince 1986) be salient in the discourse, and this brings us to Prince's third type of given/new distinction, the distinction between focus and presupposition. An open proposition (OP) is a proposition in which a 
constituent is left 'open' or unspecified; thus, a question such as (4a) will render the OP in (4b) salient.

(4) a. Where are your mittens?

b. Your mittens are $\mathrm{X}: \mathrm{X} \varepsilon$ \{places\}

('Your mittens are someplace')

That is, asking someone for the location of their mittens evokes the proposition that their mittens are in some location. Declarative statements likewise give rise to open propositions; for example, uttering (5a) renders the OPs in (5b-d), among others, salient:

(5) a. I found your mittens.

b. I found $X: X \varepsilon\{$ objects $\}$

('I found something')

c. $\mathrm{X}: \mathrm{X} \varepsilon\{$ people $\}$ found your mittens ('Someone found your mittens')

d. I did X:X\&\{activities

('I did something')

Uttering I found your mittens renders salient the notions that I found something, that someone found your mittens, and that I did something. The felicitous use of certain constructions requires that a particular OP be salient in the discourse context. The $w h$-cleft is one such construction:

(6) a. Two sets of immigration bills currently before this session of Congress are giving observers both hope and worry. What is at stake are the immigration rights of gay people, and though gay legislation generally moves slowly, voting is expected soon. (Au Courant)

b. Triggs is a lexicographer.

Over his desk hangs the 18th-century dictionary maker Samuel Johnson's ironical definition: 'A writer of dictionaries; a harmless drudge that busies himself in tracing the original, and detailing the signification of words.'

What Triggs actually does is find alert readers who recognize new words or new usages for ordinary ones.

(N.Y. Times News Service)

The wh-cleft in (6a), what is at stake are the immigration rights of gay people, is felicitous only in a context in which it is salient that something is at stake (i.e., the OP $X: X \varepsilon\{$ issues $\}$ is at stake must be salient). This OP constitutes the presupposition of the utterance, and the postcopular NP - the immigration rights of gay people - constitutes the focus, or the new information. Likewise, the wh-cleft in (6b), what Triggs actually does is find alert readers who recognize new words or new usages for ordinary ones, is felicitous only in a 
context in which it is salient that Triggs does something - i.e., when the OP Triggs does $X: X \varepsilon\{$ activities $\}$ is salient.

The contexts given in (6) clearly do render these OPs salient; conversely, if the OP is not salient, the wh-cleft is infelicitous. Thus, compare (7a) and (7b), uttered in, say, a grocery store:

(7) a. Hey, look! That's my friend Jeremy Triggs over there. He's a lexicographer. What he does is find alert readers who recognize new words or new usages for ordinary ones.

b. Hey, look! That's my friend Jeremy Triggs over there. \#What he does is find alert readers who recognize new words or new usages for ordinary ones.

In (7a), the mention of Triggs's occupation gives rise to the issue of what he does, rendering the OP salient. In (7b), however, merely sighting a friend in a grocery store does not render the OP salient, and so the $w h$-cleft is infelicitous.

\section{Correlating Form and Function}

So far we have looked at three types of given/new distinctions, all of which appear to be relevant in English, and we have already seen some examples of constructions that are sensitive to these statuses, such as inversion and whclefts. Interestingly, however, the correlation between construction and constraints on information status is not arbitrary. The type of information status to which a particular English construction is sensitive is partly predictable from its form - most notably in terms of the use of peripheral positions within the sentence. Specifically, as shown in Birner \& Ward 1998, 'preposing' constructions (that is, those that place canonically postverbal constituents in preverbal position) mark the preposed information as familiar within the discourse, while 'postposing' constructions (those that place canonically preverbal constituents in postverbal position) mark the postposed information as new, either to the discourse or to the hearer. Finally, constructions that reverse the canonical ordering of two constituents (placing a canonically preverbal constituent in postverbal position while placing a canonically postverbal constituent in preverbal position) mark the preposed information as being at least as familiar within the discourse as is the postposed information. In short, preposing places familiar information early in the sentence, and postposing places unfamiliar information late in the sentence; moreover, when it is a single constituent that is noncanonically positioned, the constraint is absolute, whereas when two arguments are noncanonically positioned (in particular, when their canonical positioning is reversed), it's their relative information status that is relevant. This situation holds for all constructions in English that involve the noncanonical placement 
of one or more constituents whose canonical position is not filled by a referential element (such as an anaphoric pronoun). The remainder of this section summarizes Birner \& Ward's (1998) discussion of preposing, postposing, and argument-reversing constructions.

First, consider the preposing in (8): ${ }^{2}$

(8) "In the early days, our productions were cheap and cheerful," says producer John Weaver of London-based Keefco. "We'd go into a seven-light studio, shoot the band in one afternoon and edit as we went along. The client would walk out with a tape that day."

Today's tapes may still be cheerful, but cheap they are not. (Newsweek, 4/18/83)

Here, the preposed cheap is discourse-old, having been explicitly evoked earlier in the discourse (Ward 1988' Birner \& Ward 1998). In addition, as shown in Ward 1988, preposing requires that an open proposition be salient in the discourse - here, the OP 'the tapes are X', where $\mathrm{X}$ is a member of the set \{cheap, expensive\}. If you replace cheap with information that's discoursenew, infelicity results, as shown in (9):

(9) "In the early days, our productions were cheap and cheerful," says producer John Weaver of London-based Keefco. "We'd go into a seven-light studio, shoot the band in one afternoon and edit as we went along. The client would walk out with a tape that day."

Today's tapes may still be cheerful, but \#commonly available they are not.

This constraint is common to constructions in English that prepose some constituent. In these cases, the discourse-old information serves as a link to the prior discourse (Birner \& Ward 1998), and its early positioning in the sentence facilitates discourse processing.

Postposing constructions, in contrast, require the postposed information to be new, either to the hearer (in the case of existential there - i.e., with be as the verb) or to the discourse (in the case of presentational there - i.e., with a non-be verb):

(10) a. What can happen is a hangup such as Rocky Smith ran into, as the independent hauler was traversing Chicago with a load of machinery that just had to get to a factory by morning. "There was this truck in front of me carrying giant steel coils, and potholes all over the place," he remembers.

(Wall Street Journal, 8/30/89)

\footnotetext{
${ }^{2}$ All of the naturally occurring examples in this section are taken from Birner \& Ward 1998.
} 
b. What can happen is a hangup such as Rocky Smith ran into, as the independent hauler was traversing Chicago with a load of machinery that just had to get to a factory by morning. "I was behind a truck, and \#there was this/the truck carrying giant steel coils, and potholes all over the place," he remembers.

In the existential there-sentence in (10a), the postposed NP represents hearernew information, and the utterance is felicitous. In (10b), on the reading in which the two instances of truck are coreferential, the truck in the existential represents previously mentioned (and hence hearer-old) information, and the use of existential there is infelicitous (Ward \& Birner 1997; Birner \& Ward 1998; cf. Abbott 1997). In the case of presentational there, as in (11), the postposed material is only required to represent discourse-new, rather than hearer-new, information:

(11) The volume of engine sound became louder and louder. Motorcycle police, a whole battalion (or whatever unit they come in) neared - took over the road - there must have been twenty of them. Behind them there appeared police vans and police buses, one, two, four, six, eight of each. And then, at last, behind these, the American military vehicles began to appear.

(Wakefield 1991: 94)

Here, the postposed NP police vans and police buses represents information that is new to the discourse; notice, however, that replacing this NP with one representing information that is hearer-old (yet still discourse-new) does not result in infelicity:

(12) The volume of engine sound became louder and louder. Motorcycle police, a whole battalion (or whatever unit they come in) neared - took over the road - there must have been twenty of them. Behind them there appeared the President of the United States. He rode in a black stretch limousine, surrounded by Secret Service members on mopeds.

Here the requirement that the postposed NP represent discourse-new information is still met and the presentational there-sentence is felicitous, despite the fact that this NP is hearer-old (on the assumption that the reader knows of the U.S. President). If, on the other hand, we replace the verb appeared with be, we have an existential there-sentence, and now the hearerold NP renders the utterance infelicitous:

(13) The volume of engine sound became louder and louder. Motorcycle police, a whole battalion (or whatever unit they come in) neared - took over the road - there must have been twenty of them. \#Behind them there was the President of the United States. He rode in a black stretch limousine, surrounded by Secret Service members on mopeds. 
Thus, both existential and presentational there require the postposed information to be new, but the type of newness differs: existential there requires this NP to represent hearer-new information, while presentational there requires only that it be discourse-new, regardless of its status within the hearer's knowledge store.

Unlike preposing and posting, whose constraints on information status are absolute, argument reversal depends for its felicity on the relative status of the two noncanonically positioned constituents. Consider the use of the passive in (14):

(14) The mayor's present term of office expires Jan. 1. He will be succeeded by Ivan Allen Jr...

(Brown Corpus)

In a passive with a by-phrase, the subject NP (here he, representing the previously evoked mayor) may not represent newer information than the NP in the $b y$-phrase (here the previously unmentioned Ivan Allen $J r$.). We do find examples in which both NPs represent discourse-old information, or both represent discourse-new information:

(15) An alert 10-year-old safety patrol boy was congratulated by police today for his part in obtaining a reckless driving conviction against a youthful motorist.

Patrolman George Kimmell, of McClellan Station, said he would recommend a special safety citation for Ralph Sisk, 9230 Vernor East, a third grader at the Scripps School, for his assistance in the case. (Brown Corpus)

Here, both the patrol boy and the police are discourse-new (in fact, the token is discourse-initial). Notice, however, that if the subject NP represents discoursenew information and the NP in the by-phrase represents discourse-old information, infelicity results:

(16) Ivan Allen Jr. will take office Jan. 1. \#The mayor will be succeeded by him.

The same constraint is seen in inversion, which likewise reverses the canonical position of two arguments (Birner 1994, 1996):

(17) a. They have a great big tank in the kitchen, and in the tank are sitting all of these pots.

b. They have all of these pots in the kitchen, and \#in a great big tank are sitting all of the pots.

(=(1) above)

In (17a), the preposed constituent (the tank) represents discourse-old information, while the postposed constituent (all of these pots) represents 
discourse-new information. Reversing the information status of these two elements, as in (17b), results in infelicity.

Thus, having briefly examined preposing, existential there, presentational there, passivization, and inversion, we see that the correlation of form and function proposed in Birner \& Ward 1998 holds. That is, preposing constructions place familiar information at the front of the sentence, postposing constructions place unfamiliar information at the end of the sentence, and argument-reversing constructions depend on the relative familiarity of the preposed and postposed information. The correlation between constructions and functions, then, is not arbitrary; on the contrary, there are broad, consistent, and predictive generalizations that can be made concerning the information-packaging functions of classes of related constructions.

\section{The Problem of 'Inferable' Information}

In breaking down information status into the categories of hearer-old/new and discourse-old/new, Prince (1992) leaves as an unresolved question the status of what she terms inferable information - i.e., information that has not been evoked in the prior discourse but which can be inferred from information that has been evoked in the prior discourse (Prince 1981; cf. Clark's (1977) 'bridging inferences'). Consider the inversions in (18):

(18) a. Labor savings are achieved because the crew is put to better use than cleaning belts manually; also eliminated is the expense of buying costly chemicals.

(WOODEXTRA, August 1988)

b. Beds ringed the room, their iron feet sinking into thick shirdiks woven in colorful patterns of birds and flowers. At the foot of each bed rested a stocky wooden chest, festooned with designs of cranes and sheep, horses and leaves.

(Wilson 1998: 133)

In (18a), the preposed phrase also eliminated represents information that would not normally be considered either discourse-old or hearer-old, since the fact that something is eliminated has not been explicitly mentioned in the prior context, nor is it assumed to constitute part of the addressee's prior knowledge. However, this information is not entirely brand-new, either; rather, it can be inferred from information presented in the prior discourse: the mention of labor savings in the first clause renders it inferable that something is being eliminated (specifically, labor). Likewise, in (18b), the previous mention of beds renders the preposed foot of each bed inferable. Here, the NP each bed in the italicized clause takes its referent from the set of beds already 
evoked in the first sentence; the foot of each bed, in turn, can be inferred on the basis of the generally known fact that a bed has a head and a foot. And in both cases, the inferable information occupies initial position in an inversion.

A preliminary set of inferential relations (that is, relations between the inferable constituent and information in the prior discourse) might include such relations as part/whole, entity/attribute, type/subtype, possession, set/subset, temporal ordering, and spatial proximity. The part/whole relation, for instance, is illustrated in (18b), given that the foot of a bed is a part of that bed. Similarly, the inversion in (19) illustrates the temporal ordering relation:

(19) The braided trumpeters came into view, followed by the Life Guards on their black chargers. Then came the Guards' band, with its flourishing drummers, and the glittering string of State coaches, each with whitebreeched, scarlet coated postillions and footmen, the horses pacing proudly...

(Thane 1947: 211)

Here, the preposed then is related to the previously evoked events of entities coming into view via a temporal relation; that is, given that the trumpeters were followed by the Life Guards, one may infer that something else will come next. The preposing in (20) illustrates the set/subset relation:

(20) I have a great deal of clothes....Most of my stuff, my mom gets at Alexander's.

(Philadelphia Inquirer, 11/6/83)

Here, most of my stuff represents a subset of the previously mentioned clothes. The preposing in (21) provides another example of the part/whole relation:

(21) A: You know this album?

B: This song I know.

(= Ward \& Prince 1991, (10a))

In this example, this song represents a part of the previously mentioned album. Notice that in each of the examples in (18)-(21), the inferential relation licenses the fronting of the inferable constituent; in (18) and (19), the inferable element appears in initial position in an inversion, and in (20) and (21), it appears in initial position in a preposing. In Birner 1994, 1996, it was argued that, for inversion at least, inferables are treated as discourse-old, in that their distribution is the same as that of explicitly evoked information: they may appear in preposed position when the postposed constituent represents either discourse-old or discourse-new information, but they may appear in postposed position only if the preposed constituent represents discourse-old information. Birner \& Ward 1998 found similar results for preposing: again, inferable constituents patterned with discourse-old constituents in that they could felicitously appear in preposed position. In both constructions, where 
discourse-new information cannot felicitously appear, inferable information cannot felicitously appear. Based on these results, one may reasonably conclude that inferable information is discourse-old.

Further investigation, however, reveals that the matter is somewhat more complex. Inferables remain a problem for two reasons. First, it is difficult to define precisely which elements are inferable in a given discourse; and second, their distribution in noncanonical syntactic constructions is not consistently that of 'old' information. These two issues will be dealt with in turn.

First, delimiting the class of information that counts as inferable is far from a straightforward matter. Intuition alone is insufficient; what is needed is a rigorous, reliable way of determining what is inferable in a given context. In Birner \& Ward 1998, inferables were defined as those informational elements that are related to previously evoked information via a salient partially-ordered set (poset) relationship (Hirschberg 1991). A poset is a set defined by a transitive partial ordering relation such that its members may be related either as higher/lower values within the set or as unordered alternates at the same level. Thus, an utterance of kitchen stands in a poset relation of 'containment' with the higher value house (since a house typically contains a kitchen) and the lower value refrigerator (since a kitchen typically contains a refrigerator), as well as the alternate value bedroom (which, like kitchen, represents something contained within a house). Notice that this containment relation is transitive: because a house contains a kitchen and a kitchen contains a refrigerator, a house contains a refrigerator. Notice also that the relationships that give rise to inferables needn't hold in every case; that is, the fact that there may exist a kitchen lacking a refrigerator does not nullify the inference from kitchen to refrigerator. Rather, it is sufficient that the relationship typically and plausibly hold.

In Birner \& Ward 1998, it is argued that preposed constituents in both preposing and inversion constitute links to the prior discourse, and that these links are related to the prior discourse via a poset relationship. Thus, poset relationships are taken to license the following preposings: ${ }^{3}$

(22) I want to have a really big kitchen someday.

a. The house itself I don't care about, but the kitchen needs to be big.

b. The refrigerator I'd like to choose myself, but I'm not very picky about stoves and sinks.

c. The bedroom I don't care about, but the kitchen needs to be big.

In (22a), prior utterance of a really big kitchen licenses the preposing of the higher poset value the house itself. Similarly, in (22b) it licenses the preposing

\footnotetext{
${ }^{3}$ A salient OP is also required for the felicity of most preposings and inversions. See Birner \& Ward 1998 for details and discussion.
} 
of the lower member the refrigerator, and in (22c) it licenses the preposing of the alternate member the bedroom.

A salient poset relationship is neither necessary nor sufficient for such a link, however, for two reasons. First, it overgenerates; and second, while poset relations are by definition transitive, some inferential relations that license preposing and inversion are not transitive. It overgenerates in that not all entities that stand in a poset relationship license preposing and inversion. For example, the set of entities typically contained within a house includes both a refrigerator and bathtub, yet (23) is infelicitous:

(23) I spent an hour cleaning out the refrigerator last night; \#in the bathtub my husband was relaxing. (cf. ...my husband was relaxing in the bathtub.)

Here, despite the fact that refrigerator and bathtub are alternate members of the set of items contained in a house, the context provided disallows the inference from refrigerator to bathtub. Hence, a poset relationship is not sufficient to license preposing. ${ }^{4}$

Moreover, not all inferential relationships that license preposing and inversion are transitive. For example, in arguing that the preposed constituent in a Topicalization (one of the two primary subtypes of preposing; see Ward 1988) must be related to the prior discourse via a poset relation, Ward \& Prince (1991) note that 'relations that are not transitive... are disallowed in felicitous Topicalization.' As evidence they give (24):

(24) a. John went into a restaurant and he asked for the menu.

b. \#John went into a restaurant and the menu he asked for.

(= Ward \& Prince 1991, (17), emphasis mine)

Here, the infelicity of the preposing in (24b) is said to be due to the fact that the relation of functional dependence linking the menu to a restaurant is not a poset relation, as evidenced by (25):

(25) a. We ate in a terrible French restaurant last night. \#The cork was green.

b. We ate in a terrible French restaurant last night. The wine was awful. The cork was green.

$$
\text { (=Ward \& Prince 1991, ex. (18)) }
$$

The felicity of the definites in (25b) indicates that wine is inferable from French restaurant, and likewise that cork is inferable from wine; however, as

\footnotetext{
${ }^{4}$ One might argue that (23) is infelicitous because it lacks an appropriate OP; however, as demonstrated in Birner \& Ward 1998, the OP requirement does not hold for those preposings and inversions whose preposed constituent is semantically locative, as in (23).
} 
seen in (25a), cork cannot be inferred from French restaurant. Ward \& Prince argue, based on these examples, that while a relation of functional dependence links French restaurant to wine and wine to cork, the inference is not transitive; thus, the relation of functional dependence is not a poset relation. However, notice that this relation does in fact license preposing:

(26) a. We ate in a terrible French restaurant last night. The wine we could tolerate, but the food was inedible.

b. We bought a terrible bottle of wine last night. The cork we had no problem with, but the color and bouquet were really bad.

Thus, either these do not exemplify the relation of functional dependence, or else functional dependence is not transitive yet does license preposing. In the latter case, functional dependence is not a poset relation (since poset relations are defined as transitive), and hence the poset relation is not a necessary condition (nor, as we saw above, a sufficient condition) for felicitous preposing. In the former case - i.e., if these are not examples of functional dependence - the fact remains that whatever relation they represent cannot be transitive (as demonstrated in (25)) and hence cannot be a poset relation, despite the fact that it licenses preposing. ${ }^{5}$ Thus, poset relations are neither necessary nor sufficient for felicitous postposing, and to define these linking relations as poset relations is therefore either incorrect or incomplete. ${ }^{6}$

I noted above that inferable information is problematic in two senses, first in that inferability is insufficiently defined, and second in that the distribution of inferable information in noncanonical syntactic constructions is not

\footnotetext{
${ }^{5}$ Another possibility is that both relations - i.e., the relation linking restaurant with wine and the relation linking wine with cork - are poset relations but that they are of distinct types. So, for example, while it is entirely plausible to consider cork to stand in a functional dependence relationship with wine (on the grounds that the cork's function is defined relative to the wine), it could be argued that this is not the same relation that links wine to restaurant. In that case, one could argue that perhaps each individual poset relation is transitive but that transitivity is not preserved across poset relations. In that case, however, we again find that the mere stipulation of a poset requirement as in Birner \& Ward 1998 is insufficiently constrained, as it would at the very least require a corollary regarding constraints on transitivity.

${ }^{6}$ Researchers in psycholinguistics have been working to develop a taxonomy of inferences that are generated during the comprehension of a discourse (Magliano \& Graesser 1991; Magliano, Baggett \& Graesser 1996). These authors restrict the inferences in question to 'knowledge-based inferences', i.e., inferences whose generation requires access to world knowledge in addition to the information presented in the prior discourse. Magliano \& Graesser list eleven categories of inference, including anaphoric reference, inference to a consequence, and inference to a superordinate goal. They do not, however, correlate these categories of inference with information packaging - i.e., the positioning of informational elements within noncanonical syntactic constructions. Thus, further research is necessary in order to determine the empirical status of these categories with respect to information structure and noncanonical word order.
} 
consistently that of old information. Having discussed the first difficulty, I will now address the second.

In delineating the distinction between discourse- and hearer-status, Prince (1992) notes that she has left the status of inferable elements as an open question. As noted above, in Birner 1994 and 1996 inferables are shown to pattern distributionally with discourse-old information in inversion, and in Birner \& Ward 1998 the same is found to be true for their distribution in preposings. Thus, the conclusion may be drawn that for noncanonical English constructions whose felicity is dependent on discourse-old status, inferable information satisfies the condition of being discourse-old. This, however, does not address the question of those constructions which are sensitive to hearerstatus rather than discourse-status. Recall from Table 1 that in Prince's framework, all information which is discourse-old is also taken to be hearerold; thus, one would expect that inferable information would behave consistently as hearer-old and never as hearer-new. However, suggestive evidence from existential there-sentences indicates that this is not the case.

As shown above, existentials require their postposed constituent to represent hearer-new information, leading to the infelicity of (13), repeated below as (27):

(27) The volume of engine sound became louder and louder. Motorcycle police, a whole battalion (or whatever unit they come in) neared - took over the road - there must have been twenty of them. \#Behind them there was the President of the United States. He rode in a black stretch limousine, surrounded by Secret Service members on mopeds.

However, an examination of naturally occurring language data shows that inferable information can felicitously appear in postposed position in an existential there-sentence, as illustrated in (28):

(28) a. There weren't the funds necessary for the project. (= Abbott 1992, (31a))

b. The audience did not think much of the new pastor, and what the new pastor thought of the audience he did not dare at the time to say. During the next weeks he looked over the situation. First of all there was the parsonage, an utterly impossible place for civilized people to live in, originally poorly conceived, apparently not repaired for years, with no plumbing or sewage, with rat-holes and rot.

(Brown Corpus)

c. If the farm is rented, the rent must be paid. If it is owned, taxes must be paid, and if the place is not free of mortgage, there will be interest and payments on the principal to take care of. (Brown Corpus) 
In (28a), the funds evoked in the postposed constituent represent inferable information on the grounds that, given a project, one can infer that funds might be required for it. This analysis is supported by the felicity of the definite NP. In (28b), in the context of a new pastor, the parsonage likewise represents inferable information. And finally, in (28c), it is inferable that a farm carrying a mortgage will require interest and payments on the principal. Thus, in each case the postposed constituent represents inferable information. These examples suggest that, at least for the purposes of postposing in an existential there-sentence, inferable information seems to be treated as hearernew. In fact, in a pilot study of 149 existentials taken from the Brown A Reportage Subcorpus, a trained coder judged that in 38 , or $25.5 \%$, of the tokens, the postverbal NP represented inferable information.

In the same context, however, these same NPs may be felicitously preposed, as in (29), suggesting that they are being treated as discourse-old information:

(29) a. The deadline was looming, and they had found significant support, but the funds necessary for the project they hadn't yet found.

b. The audience did not think much of the new pastor, and what the new pastor thought of the audience he did not dare at the time to say. During the next weeks he looked over the situation. The parsonage he could tolerate, but the church itself was in terrible disrepair.

c. If the farm is rented, the rent must be paid. If it is owned or mortgaged, the owner pays the taxes. Interest and payments on the principal the owner may find harder to pay.

Thus, for purposes of existentials the inferable entities in (28)-(29) are treated as hearer-new information, but for purposes of preposing, they are treated as discourse-old information. Notice also that information that has been explicitly evoked in the prior discourse - and which is therefore clearly both hearer-old and discourse-old - is clearly not felicitous in existentials. Compare (30a) and (30b), in which the only difference is in whether the refrigerator constitutes previously evoked or inferable information:

(30) a. Fred entered the kitchen and looked around. In one corner there was the refrigerator, and next to it was the sink.

b. Fred entered the kitchen and looked around at the sink and the refrigerator. \#In one corner there was the refrigerator, and next to it was the sink. [cf. The refrigerator was in one corner...]

In (30a), where the refrigerator is merely inferable, the existential is felicitous, whereas in (30b), where it has been explicitly evoked, the existential is 
infelicitous. Compare (30) with (31), in which the inferable refrigerator is treated as discourse-old information in an inversion and a preposing:

(31) a. Fred entered the kitchen and looked around. On top of the refrigerator was a potted plant.

b. Fred entered the kitchen and looked around. The refrigerator he spotted immediately, but it wasn't until he turned the corner that he spied the microwave.

The felicity of the refrigerator in preposed position in both the inversion in (31a) and the preposing in (31b) confirms its status as discourse-old information. Thus again, for purposes of the existential, the inferable NP is treated as hearer-new, while for purposes of preposing and inversion, it is treated as discourse-old.

What this suggests is that inferable information occupies the fourth quadrant of Prince's matrix:

Table 2: Hypothesis

Hearer-old: Hearer-new:

Discourse-old:

Discourse-new:

\begin{tabular}{|l|l|}
\hline Evoked & Inferable \\
\hline Unused & Brand-new \\
\hline
\end{tabular}

(cf. Prince 1981, 1992)

But how can this be? Recall, in particular, that this is the one combination that Prince (1992) suggests is non-occurring, on the grounds that anything that has been evoked in the prior discourse can be assumed to be known to the hearer. How is it possible for some constituent to represent information that has been evoked in the previous discourse yet is new to the hearer?

I believe the problem lies in the definitions of the terms discourse-old/new and hearer-old/new, whose parallelism is appealing but misleading. As discussed above, hearer-old information is that information which the speaker assumes is already present in the hearer's knowledge store, either by virtue of having been explicitly evoked in the discourse or by virtue of having been there before the start of the discourse, as with general world knowledge or information evoked in prior discourses. Discourse-old information, in turn, is that information which has been explicitly evoked in the prior discourse. We have seen, however, that the information treated as discourse-old encompasses a wider range of information than just that which has been explicitly evoked. 
As noted above, Birner (1996) shows that for purposes of inversion, inferable information is treated as discourse-old (as in (31a) above), and Birner \& Ward (1998) find the same to be true of preposing (as in (31b) above), and also for passivization, as in (32):

(32) After being closed for seven months, the Garden of the Gods Club will have its gala summer opening Saturday, June 3. Music for dancing will be furnished by Allen Uhles and his orchestra, who will play each

Saturday during June.

(Brown Corpus)

Here, the mention of a gala opening licenses the inference to typical components of such an event, including food, drink, dancing, and music for dancing. The NP music for dancing is therefore inferable, and it appears here in initial position in the passive clause. Thus, it is consistently the case that constructions in English that prepose discourse-old information also prepose inferable information.

Recall that in Birner \& Ward 1998, it is argued that both evoked information and inferable information provide a link to the prior discourse. Given the findings described above, I propose that it is this property that defines the class of discourse-old information - i.e., that the unifying factor is not prior evocation within the discourse, but instead the existence of an inferential link to the prior discourse. In the case of explicitly evoked information, this link is one of identity, whereas in the case of inferable information, the link is made via an inference of the sort discussed above. Notice, however, that the two cases are not really distinct: even a relationship of identity requires an inference for its establishment. For example, in (3) above, repeated here as (33), an inference is required in order to interpret the pronoun he as being linked via an identity relation to Gov. Rod Blagojevich:

(33) Gov. Rod Blagojevich, while scaling back a massive capital program, said Friday he would endorse a $\$ 3.6$ billion state construction budget that includes new money to build schools and millions of dollars for legislative pork-barrel projects.

That is to say, the reader must infer that the referent of he is Blagojevich. Thus, I would argue that all discourse-old information is in fact inferentially related to the prior discourse, whether the entity has been explicitly evoked in the prior context or is linked via some other relation.

If we think of discourse-old information in this way, its definition is not quite parallel to that of hearer-old information. Instead, I offer the following definitions for what I am terming 'D-old' and 'H-old' information: 
- D-old information: Information that is inferentially linked to the prior discourse.

- H-old information: Information assumed to be present in the hearer's knowledge store/discourse model.

(In the abbreviatory spirit of the Chomskyan D-structure and S-structure and Horn's (1984) Q-inference and R-inference, I am here using 'D-old' and ' $\mathrm{H}$ old' to evoke Prince's 'discourse' and 'hearer' statuses while simultaneously flagging the fact that I have altered their definitions slightly.)

This leaves us with the following entirely satisfactory set of information statuses:

- D-OLD, H-OLD INFORMATION: Information that is both inferentially linked to the prior discourse and (assumed to be) known to the hearer, by virtue of having been explicitly evoked. ('Evoked' information.)

- D-NEW, H-NEW INFORMATION: Information that is assumed to be new to the hearer and not inferentially linked to the prior discourse. ('Brandnew' information.)

- D-NEW, H-OLD INFORMATION: Information that is assumed to be known to the hearer, but is not inferentially linked to the prior discourse. ('Unused' information.)

- D-OLD, H-NEW INFORMATION: Information that is assumed to be new to the hearer, yet is inferentially linked to the prior discourse. ('Inferable' information.)

These descriptions correspond to the statuses listed in Table 2.

If this proposal is correct, then inferable information is that which is linked to the prior discourse, yet new to the hearer on the grounds that it does not exist in the hearer's knowledge store prior to utterance. It is clear that much work remains to be done in delimiting the types of inferential links that license the treatment of information as discourse-old. Nonetheless, the identification of inferable information as occupying Prince's fourth quadrant offers insights not only for the analysis of inferable information in noncanonical constructions, but also into the most appropriate categorizations for the study of information statuses in general.

\section{References}

Abbott, Barbara. 1992. Definiteness, Existentials, and the 'List' Interpretation. Proceedings of SALT II. Columbus, Ohio.

Abbott, Barbara. 1997. Definiteness and Existentials. Language 73:103-108. 
Abbott, Barbara. 2003. Definiteness and Indefiniteness. In Laurence R. Horn \& Gregory Ward, eds., Handbook of Pragmatics. Blackwell, Oxford, pp. 122-149.

Birner, Betty J. 1994. Information Status and Word Order: An Analysis of English Inversion. Language 70: 233-59.

Birner, Betty J. 1996. The Discourse Function of Inversion in English. Garland, New York.

Birner, Betty J. and Gregory Ward. 1994. Uniqueness, Familiarity, and the Definite Article in English. Proceedings of the Berkeley Linguistics Society 20: 93-102.

Birner, Betty J., and Gregory Ward. 1998. Information Status and Noncanonical Word Order in English. John Benjamins, Amsterdam.

Chafe, Wallace. 1976. Givenness, Contrastiveness, Definiteness, Subjects, Topics, and Point of View. In Charles Li, ed., Subject and Topic. Academic Press, New York, pp. 25-55.

Clark, Herbert H. 1977. Bridging. In Philip Nicholas Johnson-Laird and Peter Cathcart Wason, eds., Thinking: Readings in Cognitive Science. Cambridge University Press, Cambridge, pp. 411-20.

Firbas, Jan. 1966. Non-thematic Subjects in Contemporary English. Travaux Linguistiques de Prague 2: 239-56.

Grice, H. Paul. 1975. Logic and Conversation. In Peter Cole and Jerry Morgan, eds., Syntax and Semantics 3: Speech Acts. Academic Press, New York, pp. 41-58.

Halliday, Michael A. K. 1967. Notes on Transitivity and Theme in English, Part 2. Journal of Linguistics 3:199-244.

Halliday, Michael A.K. and Ruqaiya Hasan. 1976. Cohesion in English. Longman, London.

Hirschberg, Julia. 1991. A Theory of Scalar Implicature. Garland, New York.

Horn, Laurence R. 1984. Toward a New Taxonomy for Pragmatic Inference: Q-based and Rbased Implicature. In Deborah Schiffrin, ed., Meaning, Form, and Use in Context: Linguistic Applications. Georgetown University Press, Washington DC, pp. 11-42.

Kehler, Andrew. 2002. Coherence, Reference, and the Theory of Grammar. CSLI, Stanford.

Magliano, Joseph P., W. B. Baggett, \& Arthur C. Graesser. 1996. A Taxonomy of Inference Categories That May Be Generated During the Comprehension of Literary Texts. In R. J. Kreuz \& M. S. MacNealy, eds., Empirical Approaches to Literature and Aesthetics. Ablex, Norwood NJ, pp. 201- 220.

Magliano, Joseph P., \& Arthur C. Graesser. 1991. A Three-Pronged Method for Studying Inference Generation in Literary Text. Poetics 20: 193-232.

Prince, Ellen F. 1981. Toward a Taxonomy of Given/New Information. In Peter Cole, ed., Radical Pragmatics. Academic Press, New York, pp. 223-54.

Prince, Ellen F. 1986. On the Syntactic Marking of Presupposed Open Propositions. In A. Farley, P. Farley, and K.-E. McCullough, eds., Papers from the Parasession on Pragmatics and Grammatical Theory, 22nd Meeting of the Chicago Linguistic Society, pp. 208-22.

Prince, Ellen F. 1992. The ZPG Letter: Subjects, Definiteness, and Information-Status. In Sandra Thompson and William Mann, eds., Discourse Description: Diverse Analyses of a Fundraising Text. John Benjamins, Amsterdam, pp. 295-325.

Thane, E. 1947. The Light Heart. Hawthorne Books, New York.

Ward, Gregory. 1988. The Semantics and Pragmatics of Preposing. Garland, New York.

Ward, Gregory and Betty J. Birner. 1997. Response to Abbott's Discussion Note. Language 73: 109-112.

Ward, Gregory and Ellen F. Prince. 1991. On the Topicalization of Indefinite NPs. Journal of Pragmatics 16: 167-177.

Wakefield, Hannah. 1991. A Woman's Own Mystery. St. Martin's Press, New York.

Wilson, D. L. 1998. I Rode a Horse of Milk White Jade. HarperTrophy, New York. 